\title{
ON KY FAN'S INEQUALITY
}

\author{
IOAN GAVREA AND TIBERIU TRIF
}

Abstract. In this paper we prove several Ky Fan type inequalities involving certain StolarskyTobey means.

Mathematics subject classification (2000): 26D15.

Key words and phrases: Ky Fan's inequality, Stolarsky-Tobey means.

\section{REFERENCES}

[1] H. Alzer, On an inequality of Ky Fan, J. Math. Anal. Appl. 137 (1989), 168-172.

[2] H. AlzER, The inequality of Ky Fan and related results, Acta Appl. Math. 38 (1995), 305-354.

[3] N. Levinson, Generalization of an inequality of Ky Fan, J. Math. Anal. Appl. 8 (1964), 133-134.

[4] M. T. McGregor, On some inequalities of Ky Fan and Wang-Wang, J. Math. Anal. Appl. 180 (1993), 182-188.

[5] A. MCD. MERCER, A short proof of Ky Fan's arithmetic-geometric inequality, J. Math. Anal. Appl. 204 (1996), 940-942.

[6] A. MCD. Mercer, An "error term" for the Ky Fan inequality, J. Math. Anal. Appl. 220 (1998), 774-777.

[7] J. E. PeČARIĆ AND V. ŠIMIĆ, Stolarsky-Tobey mean in $n$ variables, Math. Inequal. Appl. 2 (1999), $325-341$

[8] A. O. Pittenger, The logarithmic mean in $n$ variables, Amer. Math. Monthly 92 (1985), 99-104.

[9] T. Popoviciu, Sur une inégalité de N. Levinson, Mathematica (Cluj) 6 (1964), 301-306.

[10] J. SÁNDOR AND T. TRIF, A new refinement of the Ky Fan inequality, Math. Inequal. Appl. 2 (1999), $529-533$.

[11] K. B. StOlaRSKY, Generalizations of the logarithmic mean, Math. Mag. 48 (1975), 87-92.

[12] M. D. TobeY, Two-parameter homogeneous mean value, Proc. Amer. Math. Soc. 18 (1967), 9-14.

[13] W.-L. WANG AND P.-F. WANG, A class of inequalities for symmetric functions (in Chinese), Acta Math. Sinica 27 (1984), 485-497. 